Article

\title{
Examining the Predictors of Resilience and Work Engagement during the COVID-19 Pandemic
}

\author{
Adedapo Oluwaseyi Ojo ${ }^{1}\left(\mathbb{D}\right.$, Olawole Fawehinmi $^{2}\left(\mathbb{D}\right.$ and Mohd Yusoff Yusliza ${ }^{2, *}$ \\ 1 Faculty of Management, Multimedia University, Cyberjaya 63100, Malaysia; ojo.adedapo@mmu.edu.my \\ 2 Faculty of Business, Economics and Social Development, Universiti Malaysia Terengganu, \\ Kuala Nerus 20130, Malaysia; olawolefawehinmi@outlook.com \\ * Correspondence: yusliza@umt.edu.my; Tel.: +609-668-4243
}

Citation: Ojo, A.O.; Fawehinmi, O.;

Yusliza, M.Y. Examining the

Predictors of Resilience and Work

Engagement during the COVID-19

Pandemic. Sustainability 2021, 13,

2902. https://doi.org/10.3390/

su13052902

Academic Editor: Christopher

Robin Bryant

Received: 31 January 2021

Accepted: 4 March 2021

Published: 8 March 2021

Publisher's Note: MDPI stays neutral with regard to jurisdictional claims in published maps and institutional affiliations.

Copyright: (c) 2021 by the authors. Licensee MDPI, Basel, Switzerland. This article is an open access article distributed under the terms and conditions of the Creative Commons Attribution (CC BY) license (https:// creativecommons.org/licenses/by/ $4.0 /)$.

\begin{abstract}
Previous studies have acknowledged the importance of resilience in enabling individuals to cope and bounce back from crises and unexpected situations like the COVID-19 pandemic. Thus, this study advances conservation of resources theory by investigating the job, social, and personal resources underlying employees' resilience, and the impact of resilience in stimulating job engagement amid the COVID-19 pandemic. The model was tested using data collected from 259 employees in Malaysia. Results of path modeling analysis revealed significant impacts of self-efficacy, facilitating conditions, and family and friends' support on employees' resilience. Besides, resilience was significantly associated with job engagement. Our findings suggest that management concerns for employees may not enhance employees' resilience amid the COVID-19 pandemic. Nevertheless, management could stimulate their employees' resilience by providing them with the flexibility to spend quality time with their loved ones and adequate support for enabling working conditions.
\end{abstract}

Keywords: conservation of resources; social support; self-efficacy; work engagement; resilience; COVID-19 pandemic

\section{Introduction}

Coronavirus disease 2019 (COVID-19) was first reported in Wuhan, China, in December 2019, and two months later it was declared a global pandemic by the World Health Organization (WHO). By 10 September 2020, approximately 28 million people worldwide had been infected with COVID-19, with more than 899,916 reported deaths [1]. In response to the public health crisis, many countries have implemented a lockdown order to limit physical interactions, thereby containing the spread of this highly infectious respiratory disease. However, these restrictions have disrupted daily activities, firms' operations, and supply chains. Many employees have been forced to work from home while attending to other chores like homeschooling and babysitting their children. Some have had to contend with more challenging situations like massive pay cuts, unpaid leave, or job loss. As the infection curve flattens, many regions have started easing lockdowns. Nonetheless, the likelihood of a resurgence of COVID-19 has forced individuals and organizations to adapt to the new normal.

The COVID-19 pandemic has created a climate of uncertainty among people and placed a significant burden on their inner resources to cope with the resultant challenges. Amid such a crisis, a firm's resilience has become essential to business continuity and recovery. Resilience is a concept from the positive psychology literature; it emphasizes organizations' and individuals' strengths and virtues to cope in unusual situations [2]. From the organizational perspective, resilience encapsulates "the developable capacity to rebound or bounce back from adversity, conflict, and failure or even positive events, progress, and increase responsibility" [3] (p. 702). As a positive resource, resilience enables people to navigate a stressful workplace and unexpected events like the COVID-19 pandemic. 
Consistent with social cognitive theory, human actions are shaped through interaction among environmental, personal, and individual factors. Accordingly, employees' responses to the COVID-19 pandemic can be explained from the social work environment and personal attributes. Studies have acknowledged the multifaceted nature of employee resilience, wherein it is considered static when based on personal trait and capacity, and dynamic when it emerges in response to trigger events [4]. Thus, beyond personal attributes, the dynamic process of responding to a stressful event can be enacted through individuals social support. Williams and Cooper [5] (p. 317) defined social support as "the amount of help one gets by discussing problems or situations with other people."

Although the literature has acknowledged the significance of resilience on employees' outcomes, limited attempts have been made to clarify the social antecedents of resilience in challenging situations [6-8]. Studies on employees' resilience have generally considered social support in terms of leadership and coworker support; family and friends' impact has been less examined. Considering the need to work from home during the COVID-19 pandemic, social support from family and friends is equally crucial as other resources like leadership support and task competence. Thus, drawing on the conservation of resources (COR) theory, we posit that job, social, and personal resources can influence employees' resilience. By building resilience, employees are better able to engage in their job. Beyond supervisor support, we considered the social support received from friends and family as other resources that could enhance employees' resilience. Thus, this study investigates the antecedents of resilience and their indirect effects on work engagement.

In the preceding section, we discuss COR theory and the concepts of resilience and work engagement.

\section{Literature Review}

\subsection{Conservation of Resources (COR) Theory}

COR theory is a motivation theory that explains how human behavior is shaped through the need to acquire and conserve resources that are central to survival [9]. According to COR, people experience stress when their access to essential resources is threatened, when they lose central resources, or when their effort to gain vital resources is thwarted. COR theory posits that people who lack vital resources are more vulnerable to experiencing subsequent losses, whereas those with abundant resources will have more opportunities to gain additional resources [10]. The fundamental tenet of COR theory alludes that resource loss is overly more striking than resource gain, because resource loss constitutes a significant risk to subsistence [11]. Thus, alongside its more influential magnitude than resource gain, resource loss also tends to impact people more swiftly and at an increased speed over time [9].

People must gain and conserve the essential personal, social, and material resources to respond to and cope with stress [9] effectively. Personal resources consist of skills or personality traits that help people endure tense circumstances, attain anticipated objectives, or attain additional resources. They are composed of unique traits like a sense of autonomy, self-efficacy, and optimism; whereas skills include job skills or social skills. Material resources are valued physical entities like accommodation, transportation, or work equipment. Additionally, other resources include social support from family, friends, or even supervisors [12].

Based on COR theory, studies have demonstrated the impact of safety climate on employee psychological stress [13], the influence of post-traumatic stress resulting from treating the Middle East Respiratory Syndrome virus on healthcare workers' turnover intention [14], and the impact of lack of access to relevant work tools and social support on employees' burnout [15]. COR is relevant to understanding the potential effect of the COVID-19 pandemic on work engagement as millions of employees are forced to work from home. Besides its highly contagious nature, the exponential growth of COVID-19 cases has resulted in public panic, thereby heightening individuals' stress levels. Gobbi et al. [16] contended that the increasing anxiety and depression caused by the pandemic could ham- 
per workers' productivity. Stress-related reactions in response to the pandemic may include decreased concentration, nervousness, irritability, restlessness, reduced productivity, and interpersonal conflicts [17].

\subsection{Resilience}

Resilience has been conceptualized as a personal resource that supports adaptation to adverse conditions [18]. In the field of psychology, resilience reflects one's capacity to recover after undergoing negative emotions, and flexibly adapt to the changing demands of stressful experiences [19]. Employees' resilience entails the capability to manage resources well, deal with excessive workloads, respond to and learn from mistakes and crises, and utilize change as a chance for development [20]. Through resilience, employees can effectively respond and adapt to changing circumstances and challenges [21]. Employees demonstrate resilient behavior when they utilize their personal and job-related resources to respond swiftly to uncertainty and change. Studies have demonstrated the impact of resilience in lessening job-related stress [22], psychological stress [13], burnout, and attrition [23].

Resilience is also pivotal to coping with stress and vital to staying in balance, most especially during the COVID-19 pandemic [17]. Gobbi et al. [16] noted that identifying specific risk and resilience factors is essential in developing effective tactics to ease the negative psychological impact of COVID-19. Some of the attributes of resilient employees are enthusiasm, optimism and hope, a high degree of autonomy, self-awareness and emotional literacy, flexibility and adaptability, a sense of purpose, and the ability to develop a sense of meaning from difficult and challenging situations [24]. According to Fletcher and Sarkar [25], resilience can be enhanced through targeted support from supervisors. Likewise, social support from family and friends could assist individuals in coping with traumatic situations that could be everyday hassles or major life events.

\subsection{Work Engagement}

Work engagement is an offshoot of employee engagement. Employee engagement is conceptualized as a multidimensional concept involving physical (behavior), cognitive (traits), and emotional (state) components [26]. Employee engagement is composed of work and organizational engagement $[27,28]$. Work engagement focuses on "a psychological state of fulfillment with one's task at work" [29], whereas organizational engagement concentrates on "a multidimensional motivational concept reflecting the simultaneous investment of an individual's physical, cognitive, and emotional energy in energetic, full work performance" [30]. In as much as work engagement and organizational engagement are equal components of employee engagement, this study will focus on work engagement because of the psychological context on employees and its links to meaningful outcomes for businesses and employees [31], which is crucial during the COVID-19 pandemic.

Schaufeli and Bakker [32] denoted work engagement as a positive and fulfilling jobrelated disposition characterized by vigor, dedication, and absorption. Vigor alludes to a remarkable level of energy and resilience when at work. It is the inclination to put in effort in given tasks and perseverance when encountered with difficulties. Dedication is portrayed by a sense of meaning, enthusiasm, motivation, pride, and challenge [33]. Absorption is being completely focused and intensely immersed in work without being conscious of time, thus causing difficulty separating from work [33]. Vigor and dedication are regarded as direct contrast of exhaustion and cynicism components of burnout [34]. Engaged employees possess a sense of energetic and affective link to their occupational tasks [9]. Moreover, engaged employees experience a stable condition of positive energy to their job and feel capable of meeting job demands. By contrast, disengaged workers feel emotionally detached from their job and experience lingering burnout, including tiredness and cynicism [34].

Work engagement is nurtured when job and personal resources meet the job demands [35]. Job resources are psychological, social, or organizational aspects of a job, 
including social support, performance feedback, and job autonomy, which predict individual engagement [32]. Personal resources enhance employees' self-perceived optimistic traits and strengths, often by developing self-efficacy, resilience, or optimism [36]. Employees with high levels of personal resources are expected to evaluate their ability to accomplish work demands efficiently, believe in positive outcomes, and can meet their needs by fully participating in their organizational roles [37]. A collective focus on personal and organizational resources is critical to understanding the potential roots of teachers' burnout to strengthen their engagement [38].

\subsection{Research Model and Hypotheses}

Drawing insights from the above, we contend that the key determinants of individual resilience are the availability of resources that are relevant to handling stressful events associated with the COVID-19 pandemic. Individuals with relevant support, material, and personal resources are better positioned to adapt and recover from the COVID-19 pandemic. Therefore, we propose support from family and friends, supervisors, and personal resources in terms of self-efficacy and material resources to facilitate conditions as determinants of employees' resilience. Moreover, we expect employees' resilience to be associated with work engagement. Figure 1 depicts the research model.

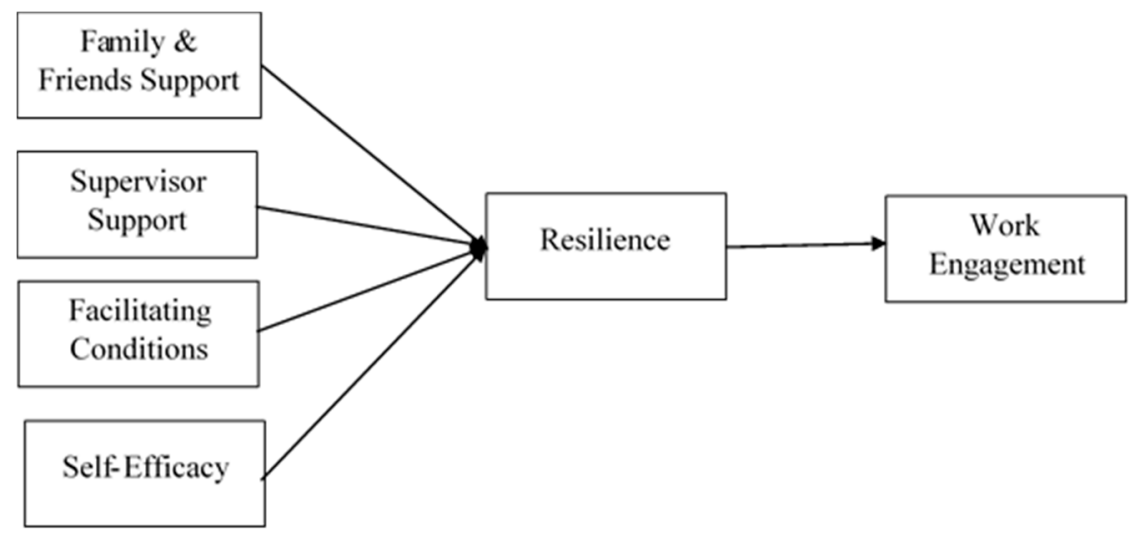

Figure 1. Research Model.

\subsubsection{Effects of Supervisor Support and Family and Friends' Support on Resilience}

Social support reflects positive or helpful social interactions that are accessible from superiors, management, and coworkers in the workplace [17]. It also refers to an individual's belief that assistance will be obtainable from other people in different situations [39,40]. Such assistance could be within an organization, such as supervisors, or outside an organization, such as family and friends [41]. COR theorists have identified that social support plays an essential role in widening the pool of available resources and replacing and reinforcing other lacking resources [10]. Furnishing employees with the appropriate resources to cope with psychological distress is necessary. With social support, employees can seek help and take advice to resolve their emotional distress and to know how they can better focus on their job. For instance, social support is found to enhance individuals' resilience to trauma [42] and natural disasters [43].

As a job resource, social support is associated with lessening work burnout [44]. Employees with social support feel that they have people they can rely on when going through psychological distress or when they need guidance on how to perform their tasks efficiently. Social support entails resources that enable the ability to handle stress [45] appropriately. Such resources include friends, significant others, and family members who furnish psychological resources such as affective support. People with these resources possess superior mental health compared with those with lesser social support [46]. Studies 
have shown that resilience can be enhanced through the availability of resources such as supervisor's support [42,47] and interactions with family and friends [48].

Employees who believe that their supervisors, friends, and family support them are more likely to evolve, develop, and better able to respond to challenging situations, such as the COVID-19 pandemic. For instance, in the healthcare sector, social support from the workplace is effective in addressing work-related stressors [49], turnover intention due to post-traumatic stress disorder [14], and promoting well-being among nurses [50]. Equally, social support from family and friends is an essential factor of well-being and resistance to stress [15]. Similarly, when faced with uncertainty and stressful situations like the COVID19 pandemic, the provision of social support could enhance employees' resilience [17]. Resilience ensures the absence of adverse outcomes in the face of adversity and can be significantly boosted in the presence of relevant social support [51]. Thus, building on COR theory of social resources, we expect that the social support from supervisors and friends, and family will enhance employee resilience [6].

Hypothesis 1 (H1). Supervisors' support is positively related to employee resilience.

Hypothesis 2 (H2). Family and friends' support is positively related to employee resilience.

\subsubsection{Effect of Facilitating Conditions on Resilience}

The availability of relevant information and communication technology (ICT) platforms and devices like email, smartphones, and virtual private networks could increase flexibility in task performance in the office and at home [52]. These technologies have radically transformed how we work and have become entrenched in every facet of life; hence, they support the new normal of working from home. During a crisis, technology could empower people to access alternative resources to reconstruct, modify, and develop new routines or patterns of action for work and socialization [53]. With the aid of relevant collaborative tools, employees can quickly move to home office settings and communicate virtually to complete their work tasks [54]. For example, through video conferencing platforms like Zoom, Webex, and Google Meet, most organizations have switched from face-to-face meetings to online meetings in compliance with the movement restriction brought about by the COVID-19 pandemic lockdown. Similarly, most schools and colleges have deployed relevant platforms to support synchronous and asynchronous online learning and teaching activities [55].

The dependence on IT infrastructure and services has become prevalent during the COVID-19 pandemic. IT provides vital tools for employees to work efficiently, collaborate, and hold meetings from home. Therefore, IT support is essential to enabling efficient task performance, remote working, and work-life balance. Wang et al. [55] confirmed the impact of IT support in enhancing educators' resilience to keep working even during the pandemic. Another study on healthcare practitioners affirmed the significance of accessible IT infrastructure and services in building healthcare workers' resilience, which, in turn, guarantees patient safety [56]. Hence, we posit that the provision of facilitating conditions, such as the availability of relevant IT infrastructure and services, could enhance employees' resilience.

Hypothesis 3 (H3). Facilitating conditions are positively related to employee resilience.

\subsubsection{Effect of Self-Efficacy on Resilience}

People's ability to successfully perform assigned tasks when faced with a new situation is shaped by their self-efficacy expectations [57]. Self-efficacy is the degree of confidence that one has in executing behaviors in a specific condition [58]. Self-efficacy affects individuals lives in extremely stressful situations but also aids the development of motivation and envisages challenging goals in life. An individual with high self-efficacy can create balance in his or her life in the form of a sense of well-being. A strong personal sense of self-efficacy helps human accomplishment and maintains a sense of psychological well-being [59]. 
Tan-Kristanto and Kiropoulos [60] argued that heightened self-efficacy levels could lead to more active coping strategies, thereby reducing the levels of depression and anxieties. By contrast, low self-efficacy is linked with negative feelings like anxiety or depression [61].

Self-efficacy impacts well-being by enabling individuals to cope with adverse situations, thereby lessening their psychological stress [43]. Self-efficacy is described as a personal factor that boosts individuals' resilience [62] and reduces psychological stress [61] most especially in a challenging situation. When employees believe in their ability to excel, even in challenging situations, their self-efficacy is boosted. However, when such tasks are easy to accomplish, their self-efficacy declines [59]. A recent study of 225 social services employees in Spain affirmed the significant impact of self-efficacy on resilience and general well-being [61]. Another study validated the significant impact of self-efficacy on lecturers' resilience, which reduces burnout [63]. Therefore, we suggest the following hypothesis.

\section{Hypothesis $4 \mathbf{( H 4 ) . ~ E m p l o y e e s ' ~ s e l f - e f f i c a c y ~ i s ~ p o s i t i v e l y ~ r e l a t e d ~ t o ~ r e s i l i e n c e . ~}$}

\subsubsection{Mediating Effects of Resilience}

Employees develop resilience when they have the support of their family and friends, which consequently leads to work engagement. When employees do not have family and friends' supports, they may experience work stress. Work stress, which can lead to work disengagement, is said to have a negative significant influence on employee resilience [64]. Research has shown that the buffer for employees to be able to endure chaotic situations is the support from friends and family. Increased resilience in employees indicates that employees will be able to avoid work burnout due to increased family and friends' support [65]. This finding shows a connection between friends' and family's support, resilience, and employees' work engagement. Family and friends' support is a personal resource at home that influences personal resources at work, such as resilience, which leads to work engagement [66].

Employees need a psychologically safe climate that supports them in overcoming work demands and performing efficiently at work. According to the Job Demands-Resources model, when employees are faced with job demands, which depletes their energy, job resource is necessary to encourage and re-energize them to sustain their work engagement [67]. A supportive organizational culture, which is a job resource, reinforces the resilience of employees, which results in work engagement. Malik and Garg [68] explained the role of a learning organization, in which supportive leadership is one of the main dimensions in the influence of employee resilience, which consequently encourages their work engagement. This finding shows that employees develop resilience on the basis of their perceived support from their organization through supervisor support, which motivates them to be engaged in their work.

The working facilities provided to employees to ensure the ease of executing their tasks will determine how quickly employees will bounce back from a traumatic episode, such as the COVID-19 pandemic, and thus become engaged with their job. For employees to bounce back from the stress caused by COVID-19 anxieties, work facilities such as dedicated ICT tools are essential. Technology use at work significantly reduces work stress [69], which results in resilience. On the basis of job resources, that is, ICT tools, employees can develop resilience, which makes them easily engaged with their work, because personal resources and job resources have been used to overcome job demands, such as stress [70].

Self-efficacy is an important personal resource that enables employees to face challenges and demands at work with an excellent outcome. Employees' belief in their capacities determines the approach to dealing with work-related situations. When employees believe that they can accomplish their tasks regardless of the job demands, they will be able to quickly bounce back from the stress attached to job demands and easily accomplish their tasks. Resilience was shown to be influenced by the heightened self-efficacy of employees, which further leads to reduced burnout among employees [63], resulting in 
work engagement [71]. Research indicated that self-efficacy significantly influences the resilience of employees [61], in which resilience further promoted work engagement among employees [68]. On the basis of this postulation, we propose the following hypotheses.

Hypothesis 5a (H5a). Resilience mediates the effect of family and friends' support on work engagement.

Hypothesis $\mathbf{5 b}(\mathbf{H} 5 \mathbf{b})$. Resilience mediates the effect of supervisor support on work engagement.

Hypothesis 5c (H5c). Resilience mediates the effect of facilitating conditions on work engagement.

Hypothesis $\mathbf{5 d}$ (H5d). Resilience mediates the effect of employees' self-efficacy on work engagement.

\subsection{Resilience and Work Engagement}

Resilience has been conceptualized as the ability to withstand stressful conditions and gain strength from adversity [25]. This concept implies that a resilient person would have the positive emotions, confidence, and optimism to keep working efficiently, regardless of surrounding conditions which could be psychologically stressful. Resilience positively predicts positive emotions [72], which eradicate stress and give room for employees to concentrate on job tasks. This notion is supported by Steinkopf et al. [73], who argued that work-related stress and resilience are inversely linked. Further, studies showed that stress among nurses is negatively related to resilience [64]. Therefore, increasing resilience among employees can reduce their job stress due to challenging or threatening conditions, such as the COVID-19 pandemic.

Employees who demonstrate positive emotions and resilience regardless of adverse circumstances are likely to be energetic and show an affective connection to perform their job tasks. Bande et al. [74] acknowledged that resilience could lead to job satisfaction and engagement. Evidence from organizations operating in pre- and post-disaster environments found that inherent resilience before exposure to a significant adverse event is associated with adaptive resilience, which is operationalized as business growth, employee engagement, and well-being in the months and years following a major crisis [75].

Based on COR theory [10], studies have established employee resilience as an aspect of personal resource, which is positively related to work engagement $[52,68,76]$. Personal resources, such as resilience, have been found to impact employees' engagement [77] significantly. Likewise, a study among nurses in China revealed resilience to be the most positively significant work engagement factor [7]. Further, Dai et al. [76] found that employees' resilience can reduce the intention to leave and enhance work engagement. Therefore, we suggest the following hypothesis.

Hypothesis 6 (H6). Resilience is positively related to work engagement.

\section{Materials and Methods}

\subsection{Data Collection}

The hypothesized research model was tested using data collected through a selfadministered survey. The draft of the questionnaire was pre-tested with three academics and three HRM managers in Malaysia. Their feedback was incorporated into the revised draft to enhance the clarity of the questions. For example, on the basis of their comments, we rephrased some of the questions and revised the purpose of the study stated in the cover letter to help potential respondents understand the study better.

An online cross-sectional survey was conducted during the COVID-19 movement control order (MCO) period in Malaysia (i.e., from 1 April 2020 to 30 May 2020). To contain the spread of COVID-19, the Malaysian government on 18 March 2020 promulgated the $\mathrm{MCO}$, which prohibits movements and gatherings across the country. The MCO mandated the closure of all business premises, except for those providing essential services. As a result, we decided to adopt an online platform (i.e., Google Form) to distribute the questionnaire to potential respondents. Given the lack of sampling frame, we purposely 
selected individuals working in the knowledge-based sectors like higher education, IT, and engineering services as potential respondents. The COVID-19 pandemic has accelerated the shift toward telecommuting and a work-from-home arrangement, and many knowledge workers can adhere to the new normal. Therefore, we emailed the link to the survey questionnaire to our contacts working in the knowledge-based sectors. The email includes a cover letter stating the study's objective and requests voluntary participation with the promise to keep respondents' anonymity. We also requested respondents to recruit their coworkers as survey participants.

From an initial sample of 274 respondents, 15 cases were deleted due to missing values. Thus, a total of 259 samples were used in the data analysis. Approximately $58.7 \%$ of respondents were male and $41.3 \%$ were female. The majority of respondents (i.e., $66.8 \%$ ) were between the ages of 36 and 45 years, $21.6 \%$ were between 25 and 35 years, $23.6 \%$ were between 46 and 55 years, and the remaining 9.7\% were above 55 years. Moreover, $80.3 \%$ were married, $16.6 \%$ were single, and $3.1 \%$ were either divorced or widowed. Ninety-three percent of respondents had at least a bachelor's degree, with $52.9 \%$ of them having a doctorate. In terms of job position, $43.2 \%$ of respondents were at the middlemanagement level and $22.8 \%$ were at the lower-management level. Seventy-two percent of respondents were from the higher education sector, $20 \%$ were from IT, and $8 \%$ were from engineering services.

\subsection{Measures}

\subsubsection{Resilience}

Resilience was measured using the brief resilience scale consisting of six items adapted from Smith et al. [78]. Responses from the positively worded items 1, 3, and 5 were maintained, whereas the other three negatively worded items 2, 4, and 6 were reversecoded. Using the seven-point Likert scale $(1=$ strongly disagree to $7=$ strongly agree), respondents were asked to indicate the extent to which they agree or disagree with the statements on resilience. Examples of these statements include "I tend to bounce back quickly after hard times", and "I have a hard time making it through stressful events". The Cronbach's alpha for this scale is 0.764 .

\subsubsection{Family and Friends' Support}

We adopted eight items from the perceived social support scale (Zimet et al.) as the measurement for family and friends' support [79]. Respondents' perceptions of the extent of social support received from family ( 4 items) and friends ( 4 items) were assessed. The items were marked using a seven-point Likert scale $(1=$ strongly disagree to $7=$ strongly agree) Sample items include "I get the emotional help and support I need from my family" and "I can count on my friends when things go wrong". We obtained a Cronbach's alpha of 0.903 .

\subsubsection{Supervisor Support}

Four items from Rhoades et al. [80] were used in assessing respondents' perceived support from their supervisors. The measurement was based on a seven-point Likert scale ( 1 = strongly disagree to 7 = strongly agree). Some of the sample items are "My work supervisor really cares about my wellbeing" and "My supervisor strongly considers my goals and values". The Cronbach's alpha was 0.950 .

\subsubsection{Employees' Self-Efficacy}

We adapted three items from Jones [57] to measure employees' self-efficacy. We asked respondents to indicate on a seven-point Likert scale $(1=$ strongly disagree to 7 = strongly agree) the extent to which they agree or disagree with the relevant statements. Sample items include "I am confident of my ability to do my job" and "I have mastered the skills necessary for my job". The Cronbach's alpha is 0.926 . 


\subsubsection{Facilitating Conditions}

Four items were adapted from Venkatesh et al. [81] to measure facilitating conditions. All the items were measured using the seven-point Likert scale $(1=$ strongly disagree to 7 = strongly agree). Sample items include "The technology platform provided by the organization is compatible with the work I do from home" and "I have the resources necessary to work from home effectively". We obtained a Cronbach's alpha value of 0.867 .

\subsubsection{Work Engagement}

Work engagement was measured using the nine items developed by Schaufeli et al. [82]. This questionnaire was rated on a seven-point Likert scale $(0=$ never to $6=$ always). Sample items were: "At my job, I feel strong and vigorous," "I am enthusiastic about my job," and "I am immersed in my work". The Cronbach's alpha for this scale was 0.925.

\section{Data Analyses and Results}

Partial least squares (PLS) technique was employed to evaluate the measurement and structural models. The PLS structural equation modeling technique is a variance-based method, which is apt for predicting exogenous variables when using revised measures [83]. Thus, with the aid of SmartPLS 3, the two-stage approach was employed in the evaluation of the model [83]. The measurement model was first evaluated to test constructs' validity and reliability, then the structural model was assessed to test the hypothesized relationships.

\subsection{Measurement Model: Reliability and Validity}

Figure 2 presents the generated PLS output of the measurement model. In addition to the reported Cronbach's alpha values, we assessed the measurement model's internal consistencies using the values of the composite reliability. The composite reliability values ranging from 0.818 to 0.968 indicate satisfactory internal consistency levels for all the constructs (see Table 1). Owing to low factor loading, we deleted an item from supervisor support (i.e., SS4) and two items from resilience (i.e., RE2 and RE4). Then we obtained factor loadings that were greater than the threshold value of 0.600 for all the constructs, except for one item from resilience with a value of 0.548 . However, this item was retained because of the acceptable value of the average variance extracted (AVE). As shown in Table 1, the AVE values ranging from 0.534 to 0.909 are above the acceptable cutoff point of 0.50 [73]. Therefore, the conditions for convergent validity were satisfied.

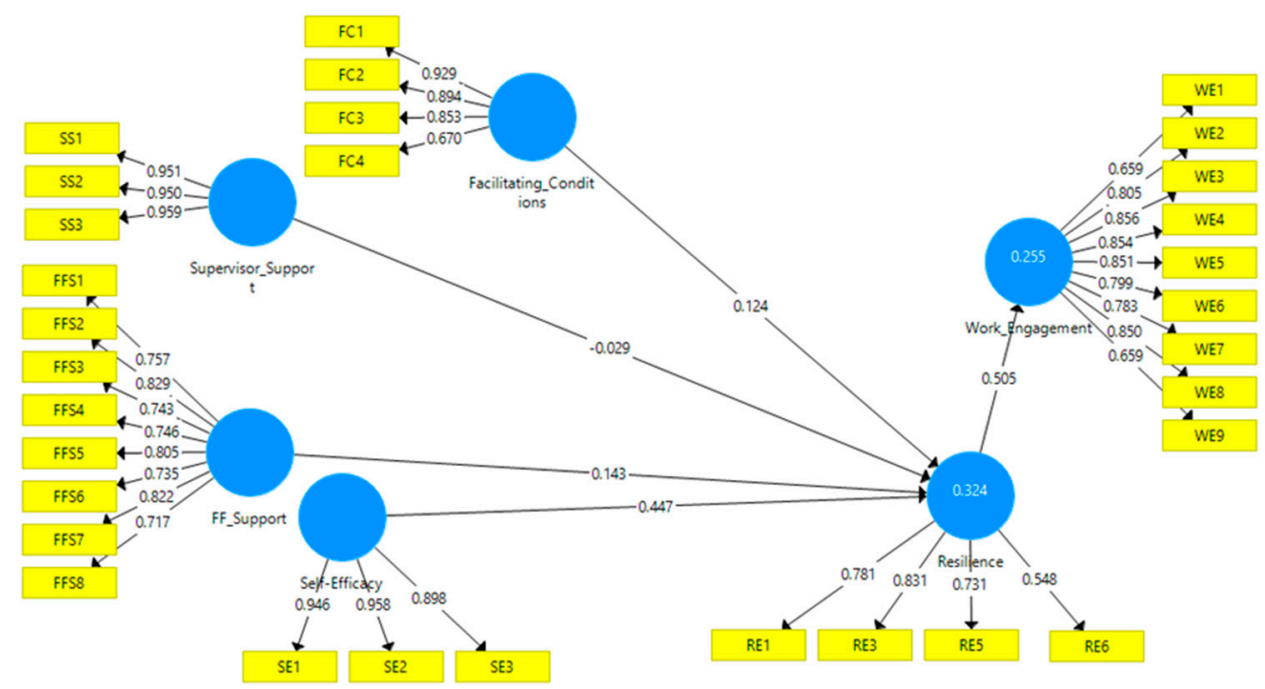

Figure 2. Measurement Model. 
Table 1. Results of Reliability and Convergent Validity.

\begin{tabular}{|c|c|c|c|c|}
\hline Construct. & Item & $\begin{array}{l}\text { Factor } \\
\text { Loading }\end{array}$ & AVE & CR \\
\hline \multirow{4}{*}{ Facilitating Conditions } & FC1 & 0.929 & 0.710 & 0.906 \\
\hline & FC2 & 0.894 & & \\
\hline & FC3 & 0.853 & & \\
\hline & FC4 & 0.670 & & \\
\hline \multirow{8}{*}{ Family and Friend Support } & FFS1 & 0.757 & 0.593 & 0.921 \\
\hline & FSS2 & 0.829 & & \\
\hline & FSS3 & 0.743 & & \\
\hline & FSS4 & 0.746 & & \\
\hline & FSS5 & 0.805 & & \\
\hline & FSS6 & 0.735 & & \\
\hline & FSS7 & 0.822 & & \\
\hline & FSS8 & 0.717 & & \\
\hline \multirow{3}{*}{ Self-Efficacy } & SE1 & 0.946 & 0.872 & 0.953 \\
\hline & SE2 & 0.958 & & \\
\hline & SE3 & 0.898 & & \\
\hline \multirow{3}{*}{ Supervisor Support } & SS1 & 0.951 & 0.909 & 0.968 \\
\hline & SS2 & 0.950 & & \\
\hline & SS3 & 0.959 & & \\
\hline \multirow{4}{*}{ Resilience } & RE1 & 0.781 & 0.534 & 0.818 \\
\hline & RE3 & 0.831 & & \\
\hline & RE5 & 0.731 & & \\
\hline & RE6 & 0.548 & & \\
\hline \multirow{9}{*}{ Work Engagement } & WE1 & 0.659 & 0.631 & 0.938 \\
\hline & WE2 & 0.805 & & \\
\hline & WE3 & 0.856 & & \\
\hline & WE4 & 0.854 & & \\
\hline & WE5 & 0.851 & & \\
\hline & WE6 & 0.799 & & \\
\hline & WE7 & 0.783 & & \\
\hline & WE8 & 0.85 & & \\
\hline & WE9 & 0.659 & & \\
\hline
\end{tabular}

We considered the two main methods for assessing discriminant validity. First, we compared the root-squared values of AVEs with the corresponding correlation coefficients. As shown in Table 2, the root-squared values of AVEs are of higher value than the pair of correlation coefficients for the associated constructs, thereby satisfying the conditions for discriminant validity [84].

Table 2. Fornell Lacker Discriminant Validity Test.

\begin{tabular}{lcccccc}
\hline \multicolumn{1}{c}{ Construct } & $\mathbf{1}$ & $\mathbf{2}$ & $\mathbf{3}$ & $\mathbf{4}$ & $\mathbf{5}$ & $\mathbf{6}$ \\
\hline 1. Family and Friends Support & 0.770 & & & & & \\
2. Facilitating Conditions & 0.432 & 0.843 & & & & \\
3. Resilience & 0.357 & 0.325 & 0.731 & & & \\
4. Self-Efficacy & 0.389 & 0.348 & 0.537 & 0.934 & & \\
5. Supervisor Support & 0.456 & 0.553 & 0.243 & 0.309 & 0.953 & \\
6. Work Engagement & 0.380 & 0.417 & 0.505 & 0.574 & 0.362 & 0.794 \\
\hline
\end{tabular}

Second, we examined the heterotrait-monotrait ratio of correlations (HTMT). In line with [85] recommendations, the HTMT ratios are lower than the threshold value of 0.85 , thereby confirming discriminant validity (see Table 3). 
Table 3. Heterotrait-Monotrait Ratio of Correlations (HTMT).

\begin{tabular}{lccccc}
\hline \multicolumn{1}{c}{ Construct } & $\mathbf{1}$ & $\mathbf{2}$ & $\mathbf{3}$ & $\mathbf{4}$ & $\mathbf{5}$ \\
\hline 1. Family and Friend Support & & & & & \\
2. Facilitating Conditions & 0.492 & & & & \\
3. Resilience & 0.422 & 0.383 & & & \\
4. Self-Efficacy & 0.420 & 0.367 & 0.666 & & \\
5. Supervisor_Support & 0.502 & 0.632 & 0.282 & 0.329 & \\
6. Work_Engagement & 0.412 & 0.453 & 0.619 & 0.618 & 0.384 \\
\hline
\end{tabular}

\subsection{Structural Model: Hypotheses Testing}

To test the hypothesized relationships, we examined the results of the structural model for the standardized path coefficients from the bootstrapping procedure (with a resample of 5000$), \mathrm{R}^{2}$, effect size $\left(\mathrm{f}^{2}\right)$, and predictive relevance [86]. Figure 3 displays the output of the bootstrapping procedure.

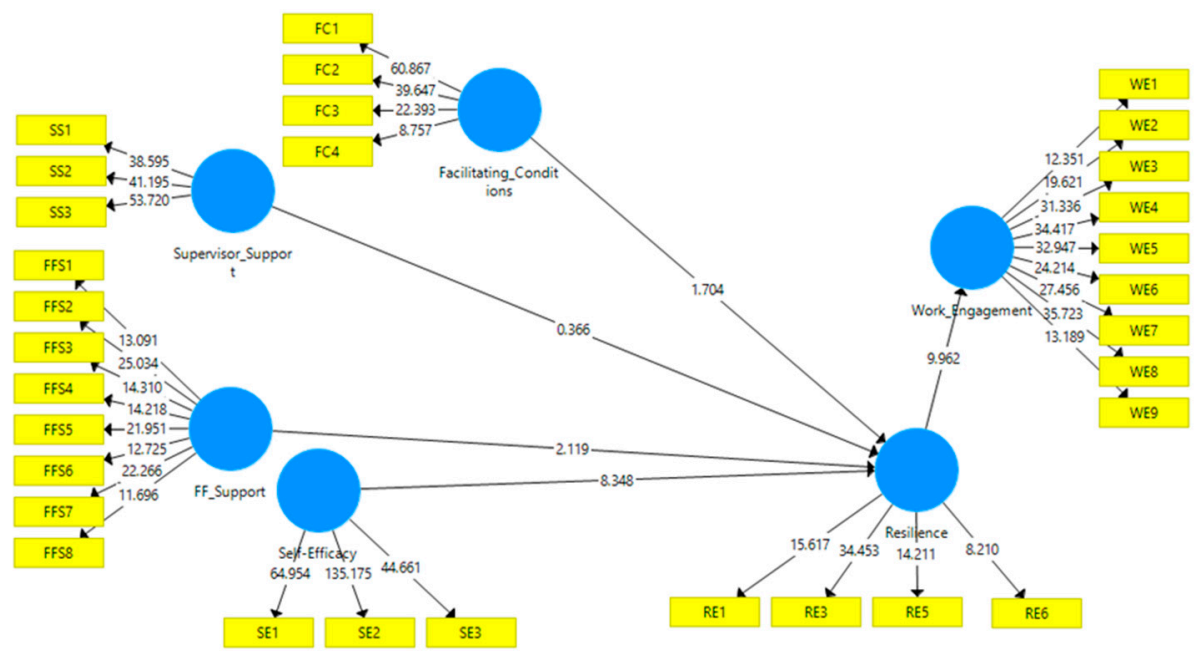

Figure 3. Structural Model.

As hypothesized, family and friends' support was significantly related to resilience $(\beta=0.143, z=2.119, p<0.05)$. However, the data did not support the significant effect of social support from supervisor on resilience $(\beta=-0.029, z=0.366, p>0.05)$. Facilitating conditions was significantly related to resilience $(\beta=0.124, \mathrm{z}=1.704, p>0.05)$, whereas self-efficacy had the most significant impact on resilience $(\beta=0.447, \mathrm{z}=8.348, p>0.001)$. Besides, the effect of resilience was significant on work engagement $(\beta=0.505, z=9.962$, $p>0.001$ ). Thus, we found support for the $\mathrm{H} 1, \mathrm{H} 3, \mathrm{H} 4$, and $\mathrm{H} 5$, but not $\mathrm{H} 2$.

Furthermore, the $\mathrm{R}^{2}$ value of 0.324 for resilience indicates that family and friends' support, facilitating conditions, and self-efficacy can explain $32.4 \%$ of the variance in resilience; whereas resilience can explain $25.5 \%$ of the variance in work engagement (i.e., $\mathrm{R}^{2}=0.255$ ). In evaluating the $\mathrm{f}^{2}$, we followed the guidelines of Vidaver-Cohen [87], which suggest $0.02,0.15$, and 0.35 as small, medium, and large effects, respectively. Our results indicate a medium effect for self-efficacy $\left(\mathrm{f}^{2}=0.237\right)$ and small effects for family and friends support $\left(\mathrm{f}^{2}=0.021\right)$ and facilitating conditions $\left(\mathrm{f}^{2}=0.015\right)$. Moreover, the data support a relatively large effect size for resilience $\left(\mathrm{f}^{2}=0.343\right)$.

Following the PLS prediction procedure, we evaluated the predictive power of the exogenous variables on resilience and resilience on employee engagement. In line with Shmueli et al. [88], we compared the root-mean-squared error values of the PLS model with the linear regression (LM) model benchmark. As shown in Table 4, the PLS model generated lower prediction errors than the LM model for all the indicators of resilience, and 
similar results were obtained for six out of the nine indicators for employee engagement, that is, $66.66 \%$. Therefore, our model has high predictive power.

Table 4. PLS Predict Results.

\begin{tabular}{ccccc}
\hline Item & PLS (RMSE) & LM (RMSE) & PLS-LM & Q $^{2}$ predict \\
\hline RE1 & 1.226 & 1.306 & -0.080 & 0.189 \\
RE3 & 1.190 & 1.222 & -0.032 & 0.193 \\
RE5 & 1.395 & 1.460 & -0.065 & 0.153 \\
RE6 & 2.048 & 2.103 & -0.055 & 0.084 \\
WE1 & 1.200 & 1.252 & -0.052 & 0.093 \\
WE2 & 1.104 & 1.112 & -0.008 & 0.157 \\
WE3 & 0.964 & 0.955 & 0.009 & 0.196 \\
WE4 & 0.950 & 0.950 & 0.000 & 0.186 \\
WE5 & 1.167 & 1.135 & 0.032 & 0.185 \\
WE6 & 1.098 & 1.101 & -0.003 & 0.175 \\
WE7 & 0.868 & 0.879 & -0.011 & 0.176 \\
WE8 & 1.031 & 1.036 & -0.005 & 0.193 \\
WE9 & 1.091 & 1.102 & -0.011 & 0.144 \\
\hline
\end{tabular}

\subsection{Testing the Mediating Effects of Resilience}

The mediating effects were assessed following the bootstrapping technique, a nonparametric resampling procedure for evaluating indirect paths $[89,90]$. In line with Hair et al. [86], we assessed the mediating effects of resilience on the relationships between the determinants and work engagement. Accordingly, the indirect effects were evaluated using 5000 bootstrap samples. The level of significance of these effects was assessed using the beta coefficient, $\mathrm{p}$-value, and bias-corrected confidence intervals (see Table 5). On the basis of the values of the beta coefficient (0.102), $p$-value (0.001), and the bias-corrected confidence intervals (0.051-0.159), which do not lie within zero, we confirmed the significance of resilience in mediating the effect of self-efficacy on work engagement. However, the mediating effects of resilience were not supported for the other determinants. For the direct effects, only self-efficacy and facilitating conditions were significantly related with work engagement. Thus, our findings indicate that self-efficacy can directly and indirectly influence work engagement through resilience. However, facilitating conditions has only direct influence on work engagement.

Table 5. Results of Mediating Effects of Resilience.

\begin{tabular}{|c|c|c|c|c|c|c|c|c|c|}
\hline Hypothesis & Description & $\begin{array}{l}\text { Direct } \\
\text { Effect }\end{array}$ & $\begin{array}{l}\text { 95\% Confidence } \\
\text { Interval }\end{array}$ & t Value & $p$-Value & $\begin{array}{l}\text { Indirect } \\
\text { Effect }\end{array}$ & $\begin{array}{l}\text { 95\% Confidence } \\
\text { Interval }\end{array}$ & t Value & $p$-Value \\
\hline $\mathrm{H} 5 \mathrm{a}$ & $\begin{array}{c}\text { Friend \& Family Support } \\
\rightarrow \text { Work Engagement }\end{array}$ & 0.063 & $-0.051-0.162$ & 0.976 & 0.165 & 0.032 & $0.005-0.069$ & 1.635 & 0.051 \\
\hline $\mathrm{H} 5 \mathrm{~b}$ & $\begin{array}{c}\text { Supervisor Support } \rightarrow \\
\text { Work Engagement }\end{array}$ & 0.090 & $-0.012-0.192$ & 1.452 & 0.073 & -0.006 & $-0.036-0.028$ & 0.316 & 0.376 \\
\hline $\mathrm{H} 5 \mathrm{c}$ & $\begin{array}{c}\text { Facilitating conditions } \\
\text { Work Engagement }\end{array}$ & 0.145 & $0.024-0.269$ & 1.913 & 0.028 & 0.027 & $0.000-0.063$ & 1.381 & 0.084 \\
\hline $\mathrm{H} 5 \mathrm{~d}$ & $\begin{array}{c}\text { Self-Efficacy Work } \rightarrow \\
\text { Engagement }\end{array}$ & 0.352 & $0.220-0.470$ & 4.538 & 0.000 & 0.102 & $0.051-0.159$ & 3.087 & 0.001 \\
\hline
\end{tabular}

\section{Discussion}

Our results support the importance of support and personal resources in reinforcing employees' resilience in the face of anxieties and uncertainties, thus enhancing work engagement during the COVID-19 pandemic. We found support for family and friends' support in enhancing employees' abilities to cope with the stress associated with the outbreak of the COVID-19 pandemic. As a consequence of the lockdown initiated to contain the spread of COVID-19, most employees have been forced to work from home, heightening the level of stress with the need to perform their job tasks concurrently with 
homeschooling their children and attending to other household chores. Our study revealed that employees with appropriate support from family and friends are better positioned to cope with the unexpected stress associated with the pandemic. Therefore, employees' abilities to recover from stressful events could be enhanced by spending time with family and friends and sharing concerns with them. This finding is consistent with the previous studies, which demonstrated the influence of family and friends in enhancing employees' resilience to traumatic situations [42].

Contrary to past studies [47], supervisor support was not significantly associated with employees' resilience. The unexpected finding could be due to the dire and peculiar situation of COVID-19, which may result in extreme psychological anxieties, thereby incapacitating supervisors' support for employees' resilience. Wang et al. [62] revealed that workplace support may not influence employees' resilience when employees feel more comfortable sharing their problems and anxieties with family members and friends. Family and friends' support has become essential in stimulating resilience in the current pandemic that has resulted in social distancing. Social distancing entails keeping space between people who are not from the same household [91]. Having people around to share the lonely moments of working from home could positively influence one's state of mind, thus emphasizing the importance of non-organizational support in employees' resilience and coping mechanisms at work. Respondents' profile in terms of job position could be another plausible reason for the non-significant effect of supervisor support. Most respondents are professionals with high educational attainment and at the middle or upper management levels. Hence, they are more likely to work independently of supervision support.

Moreover, our findings revealed the significant influence of facilitating conditions on employees' resilience. This finding indicates that by providing employees with enabling conditions to work during a pandemic like COVID-19, organizations can enhance their abilities to bounce back from fears and anxieties. Moreover, this finding aligns with that of Wang et al. [55], who revealed that facilitating conditions in terms of providing IT support and resources is critical to enabling employees' resilience during stressful situations like the COVID-19 pandemic.

The data also support the significant effect of self-efficacy on employees' resilience. This finding is consistent with previous studies [61-63]. According to Wang et al. [62], individuals who are confident in their abilities to accomplish job tasks are more likely to develop the resilience to bounce back from adverse situations like a pandemic. Accordingly, our study reaffirms the pivotal role of self-efficacy in ensuring that employees bounce back from their state of anxieties, which, in turn, could enable them to retain heightened productivity through job engagement.

Regarding the mediating role of resilience, only the relationship between self-efficacy and work engagement was supported. Thus, employees with a high level of confidence in their abilities to perform job tasks can recover quickly from stress induced by a global pandemic like COVID-19. Such confidence could enhance their work engagement. This result corroborates the social cognitive theory proposition on the role of self-efficacy in enabling resilience for a beneficial job outcome [61]. Our study further demonstrates work engagement as the outcome of resilience developed through self-efficacy. Although facilitating conditions and family and friends' support were significant predictors of resilience, the mediating effects of resilience were not significant on work engagement for these factors. Therefore, the respective effects of these factors on resilience do not contribute to deepening work engagement.

The possible reasons for the non-significant mediating effect of resilience are that even though family and friends' support encouraged employees to bounce back from their anxieties and worries during the COVID-19 pandemic, such resilience was not directed toward employee engagement due to possible factors such as attitude toward working during the COVID-19 pandemic. The next facilitation condition, such as adequate ICT facilities to work remotely, developed the resilience of employees. Nevertheless, it was not enough to encourage work engagement because employees were still trying to get accustomed to the 
new way of working. Resilience was unable to mediate the link between supervisor support and work engagement, because during the COVID-19 pandemic, supervisor support may have been very limited due to the uncertain situation in the organization.

As hypothesized, resilience was significantly associated with employees' engagement. Previous studies revealed that employees' abilities to bounce back from a dire situation are linked substantially with job engagement [68]. Therefore, employees must cultivate the personal resources of resilience, enabling them to be optimistic, tenacious, and strong in the face of difficulties or uncertainties. These attributes will stimulate their work engagement.

\subsection{Theoretical Implications}

This study advances COR theory by empirically demonstrating the factors of resilience and the implication of resilience in stimulating employees' engagement amid the COVID19 pandemic. Given the disruption and stress emanating from the pandemic, employees resilience could be shaped through social support from family and friends, supervisor, and personal resource in terms of self-efficacy and material resource in terms of facilitating conditions. The influence of resilience on employees' work engagement was also confirmed, which shows that resource gain, such as managing stress, will encourage employees' work engagement.

\subsection{Practical Implications}

This study demonstrates the importance of organizational support in providing the essential facilities to ease employees' work productivity, most especially during uncertain situations like a pandemic. Such facilities include efficient IT infrastructure for easy access to relevant databases and information from remote locations. Facilities need to be userfriendly and secure to encourage employees' acceptance. Besides, non-organizational support from family and friends is essential to building employees' resilience. Thus, the top management should incorporate in their organizational policies and strategies flexible practices like work-life balance. To support employees working from home, through job redesign, organizations could offer some level of flexibility in terms of task performance. Such flexibility could enable them to juggle between their assigned task and housekeeping responsibilities, thereby aiding them with the necessary resources to cope with stressful conditions. Flexibility can also enable employees to spend quality time with their loved ones, thereby lessening psychological stress by sharing their worries and concerns with them.

The top management and supervisors should encourage and support their employees to develop resources that could enhance their resilience and job engagement. Further, top management and supervisors can empower employees to have heightened confidence in the ability to perform their tasks. Employees should be recognized for their performance; such recognition will increase their confidence in performing their work even during challenging situations.

\section{Conclusions}

The present study contributes to existing knowledge on COR theory's relevance in explaining how employees' engagement could be optimized during a state of psychological stress such as the COVID-19 pandemic. Our findings demonstrate the influences of family and friends' support, self-efficacy, and facilitating conditions on employees' resilience and how resilience affects work engagement during stressful situations. Therefore, when resource loss (psychological stress and anxieties) due to the COVID-19 pandemic is lower than resource gain (social support, self-efficacy, facilitating condition), employees can cope and perform much better, thereby enhancing their job engagement.

Notwithstanding the above contributions, this study has limitations that could be addressed in future studies. The present study was based on a sample of 259 employees across different industry sectors in Malaysia. Thus, future studies are implored to extend our model by examining sectoral differences in employees' resilience factors. Beyond 
the emphasis on the influence of transformational leadership in enhancing employees' work engagement [92], subsequent studies are encouraged to investigate the mediating influence of resilience between transformational leadership and work engagement amid the COVID-19 pandemic. The effect of proactive personality in linking employees' resources such as family and friends' supports and facilitating conditions to engagement is another promising future research area. Proactive personality has been found to influence work engagement [93]. Thus, future studies are implored to investigate the moderating role of proactive personality on family and friends' supports and facilitating conditions on work engagement. Another factor that can be considered in future studies is career adaptability, which is a form of resilience essential in sustaining employees' stability when faced with adversity [94]. Furthermore, when employees feel empowered to perform their tasks, such emotion results in job satisfaction and commitment [95]. Hence, future studies can examine psychological empowerment as a predictor of employee resilience and job engagement. Additionally, the COVID-19 pandemic is a wakeup call for organizations to be innovative by promoting the use of ICTs and Internet of Things to accomplish organizational goals. The innovative competence of leaders plays a major role in influencing the innovative capacity of an organization [96]. Therefore, future studies should investigate the innovative capacity of leaders during the COVID-19 pandemic and their effect on the innovative capacity of an organization to excel during a pandemic.

Author Contributions: Conceptualization, A.O.O. and O.F.; methodology, A.O.O.; software, A.O.O., O.F. and M.Y.Y.; validation, A.O.O., O.F. and M.Y.Y.; formal analysis, A.O.O.; investigation, A.O.O., O.F. and M.Y.Y.; resources, A.O.O., O.F. and M.Y.Y.; data curation, A.O.O.; writing-original draft preparation A.O.O., O.F. and M.Y.Y.; writing-review and editing, A.O.O. and O.F.; visualization, A.O.O. and O.F.; supervision, A.O.O.; project administration, A.O.O.; funding acquisition, M.Y.Y. and A.O.O. All authors have read and agreed to the published version of the manuscript.

Funding: This research received no external funding.

Institutional Review Board Statement: Not applicable.

Informed Consent Statement: Informed consent was obtained from all subjects involved in the study.

Data Availability Statement: Data will be available on request.

Acknowledgments: Many thanks to everyone who participated in this study survey during the COVID-19 pandemic. Your contributions to this study are immeasurable.

Conflicts of Interest: The authors declare no conflict of interest.

\section{References}

1. World Health Organization WHO Coronavirus Disease (COVID-19) Dashboard; 2020. Available online: https://covid19.who.int/ (accessed on 10 September 2020).

2. Cooke, F.L.; Cooper, B.; Bartram, T.; Wang, J.; Mei, H. Mapping the relationships between high-performance work systems, employee resilience and engagement: A study of the banking industry in China. Int. J. Hum. Resour. Manag. 2016, 30, 1239-1260. [CrossRef]

3. Luthans, F. The need for and meaning of positive organizational behavior. J. Organ. Behav. 2002, 23, 695-706. [CrossRef]

4. Liu, Y.; Cooper, C.L.; Tarba, S.Y. Resilience, wellbeing and HRM: A multidisciplinary perspective. Int. J. Hum. Resour. Manag. 2016, 30, 1227-1238. [CrossRef]

5. Williams, S.; Cooper, C.L. Measuring occupational stress: Development of the Pressure Management Indicator. J. Occup. Health Psychol. 1998, 3, 306-321. [CrossRef]

6. Bardoel, E.A.; Pettit, T.M.; De Cieri, H.; McMillan, L. Employee resilience: An emerging challenge for HRM. Asia Pac. J. Hum. Resour. 2014, 52, 279-297. [CrossRef]

7. Cao, X.; Chen, L. Relationships among social support, empathy, resilience and work engagement in haemodialysis nurses. Int. Nurs. Rev. 2019, 66, 366-373. [CrossRef] [PubMed]

8. Cooke, F.L.; Wang, J.; Bartram, T. Can a Supportive Workplace Impact Employee Resilience in a High Pressure Performance Environment? An Investigation of the Chinese Banking Industry. Appl. Psychol. 2019, 68, 695-718. [CrossRef]

9. Hobfoll, S.E.; Halbesleben, J.; Neveu, J.-P.; Westman, M. Conservation of Resources in the Organizational Context: The Reality of Resources and Their Consequences. Annu. Rev. Organ. Psychol. Organ. Behav. 2018, 5, 103-128. [CrossRef] 
10. Hobfoll, S.E. Conservation of resources: A new attempt at conceptualizing stress. Am. Psychol. 1989, 44, 513-524. [CrossRef] [PubMed]

11. Hobfoll, S.E. Conservation of resource caravans and engaged settings. J. Occup. Organ. Psychol. 2011, 84, 116-122. [CrossRef]

12. Courtois, C.A.; Ford, J.D. Treating Complex Traumatic Stress Disorders: An Evidence-Based Guide; Courtois, C.A., Ford, J.D., Eds.; Guilford Press: New York, NY, USA, 2009.

13. Chen, Y.; McCabe, B.; Hyatt, D. Impact of individual resilience and safety climate on safety performance and psychological stress of construction workers: A case study of the Ontario construction industry. J. Saf. Res. 2017, 61, 167-176. [CrossRef]

14. Jung, H.; Jung, S.Y.; Lee, M.H.; Kim, M.S. Assessing the Presence of Post-Traumatic Stress and Turnover Intention among Nurses Post-Middle East Respiratory Syndrome Outbreak: The Importance of Supervisor Support. Work. Health Saf. 2020, 68, 337-345. [CrossRef] [PubMed]

15. Kim, J.S.; Choi, J.S. Factors Influencing Emergency Nurses' Burnout During an Outbreak of Middle East Respiratory Syndrome Coronavirus in Korea. Asian Nurs. Res. 2016, 10, 295-299. [CrossRef]

16. Gobbi, S.; Płomecka, M.B.; Ashraf, Z.; Radziński, P.; Neckels, R.; Lazzeri, S.; Dedić, A.; Bakalović, A.; Hrustić, L.; Skórko, B.; et al. Worsening of Preexisting Psychiatric Conditions During the COVID-19 Pandemic. Front. Psychiatry 2020, 11. [CrossRef] [PubMed]

17. Vinkers, C.H.; van Amelsvoort, T.; Bisson, J.I.; Branchi, I.; Cryan, J.F.; Domschke, K.; Howes, O.D.; Manchia, M.; Pinto, L.; de Quervain, D.; et al. Stress resilience during the coronavirus pandemic. Eur. Neuropsychopharmacol. 2020, 35, 12-16. [CrossRef] [PubMed]

18. Caniëls, M.C.J.; Baaten, S.M.J. How a Learning-Oriented Organizational Climate is Linked to Different Proactive Behaviors: The Role of Employee Resilience. Soc. Indic. Res. 2018, 143, 561-577. [CrossRef]

19. Niitsu, K.; Houfek, J.F.; Barron, C.R.; Stoltenberg, S.F.; Kupzyk, K.A.; Rice, M.J. A Concept Analysis of Resilience Integrating Genetics. Issues Ment. Health Nurs. 2017, 38, 896-906. [CrossRef] [PubMed]

20. Kuntz, J.; Connell, P.; Näswall, K. Workplace resources and employee resilience: The role of regulatory profiles. Career Dev. Int. 2017, 22, 419-435. [CrossRef]

21. Franken, E.; Plimmer, G.; Malinen, S. Paradoxical leadership in public sector organisations: Its role in fostering employee resilience. Aust. J. Public Adm. 2020, 79, 93-110. [CrossRef]

22. Kuntz, J.R.C.; Näswall, K.; Malinen, S. Resilient Employees in Resilient Organizations: Flourishing Beyond Adversity. Ind. Organ. Psychol. 2016, 9, 456-462. [CrossRef]

23. Salmela-Aro, K.; Upadyaya, K. Role of demands-resources in work engagement and burnout in different career stages. J. Vocat. Behav. 2018, 108, 190-200. [CrossRef]

24. Grant, L.; Kinman, G. 'Bouncing Back?' Personal Representations of Resilience of Student and Experienced Social Workers. PRACTICE 2013, 25, 349-366. [CrossRef]

25. Fletcher, D.; Sarkar, M. Psychological Resilience. Eur. Psychol. 2013, 18, 12-23. [CrossRef]

26. Kahn, W.A. Psychological conditions of personal engagement and disengagement at work. Acad. Manag. J. 1990, $33,692-725$.

27. Saks, A.M. Antecedents and consequences of employee engagement revisited. J. Organ. Eff. People Perform. 2019, 6, 19-38. [CrossRef]

28. Saks, A.M. Antecedents and consequences of employee engagement. J. Manag. Psychol. 2006, 21, 600-619. [CrossRef]

29. Wefald, A.J.; Downey, R.G. Job engagement in organizations: Fad, fashion, or folderol? J. Organ. Behav. 2008, 30, 141-145. [CrossRef]

30. Rich, B.L.; Lepine, J.A.; Crawford, E.R. Job Engagement: Antecedents and Effects on Job Performance. Acad. Manag. J. 2010, 53, 617-635. [CrossRef]

31. Soares, M.E.; Mosquera, P. Fostering work engagement: The role of the psychological contract. J. Bus. Res. 2019, 101, 469-476. [CrossRef]

32. Schaufeli, W.B.; Bakker, A.B. Job demands, job resources, and their relationship with burnout and engagement: A multi-sample study. J. Organ. Behav. 2004, 25, 293-315. [CrossRef]

33. Schaufeli, W.B.; Salanova, M.; González-Romá, V.; Bakker, A.B. The Measurement of Engagement and Burnout: A Two Sample Confirmatory Factor Analytic Approach. J. Happiness Stud. 2002, 3, 71-92. [CrossRef]

34. Bakker, A.B.; Demerouti, E.; Sanz-Vergel, A.I. Burnout and Work Engagement: The JD-R Approach. Annu. Rev. Organ. Psych. 2014, 1, 389-411. [CrossRef]

35. Bakker, A.B.; Demerouti, E. Towards a model of work engagement. Career Dev. Int. 2008, 13, 209-223. [CrossRef]

36. Vuori, J.; Toppinen-Tanner, S.; Mutanen, P. Effects of resource-building group intervention on career management and mental health in work organizations: Randomized controlled field trial. J. Appl. Psychol. 2012, 97, 273-286. [CrossRef]

37. Knight, C.; Patterson, M.; Dawson, J. Building work engagement: A systematic review and meta-analysis investigating the effectiveness of work engagement interventions. J. Organ. Behav. 2017, 38, 792-812. [CrossRef]

38. Lauermann, F.; König, J. Teachers' professional competence and wellbeing: Understanding the links between general pedagogical knowledge, self-efficacy and burnout. Learn. Instr. 2016, 45, 9-19. [CrossRef]

39. Cobb, S. Social Support as a Moderator of Life Stress. Psychosom. Med. 1976, 38, 300-314. [CrossRef]

40. Mayo, M.; Sanchez, J.I.; Pastor, J.C.; Rodriguez, A. Supervisor and coworker support: A source congruence approach to buffering role conflict and physical stressors. Int. J. Hum. Resour. Manag. 2012, 23, 3872-3889. [CrossRef] 
41. McCormack, H.M.; MacIntyre, T.E.; O'Shea, D.; Campbell, M.J.; Igou, E.R. Practicing What We Preach: Investigating the Role of Social Support in Sport Psychologists' Well-Being. Front. Psychol. 2015, 6, 1854. [CrossRef] [PubMed]

42. Sippel, L.M.; Pietrzak, R.H.; Charney, D.S.; Mayes, L.C.; Southwick, S.M. How does social support enhance resilience in the trauma-exposed individual? Ecol. Soc. 2015, 20. [CrossRef]

43. Raman, M.; Ojo, A.O.; Dorasamy, M. A.O.; Dorasamy, M. A stakeholder perspective in managing floods in Malaysia. In WIT Transactions on the Built Environment; WIT Press: Ashurst, UK, 2015; Volume 1, pp. 1171-1181.

44. Ju, C.; Lan, J.; Li, Y.; Feng, W.; You, X. The mediating role of workplace social support on the relationship between trait emotional intelligence and teacher burnout. Teach. Teach. Educ. 2015, 51, 58-67. [CrossRef]

45. Brackett, M.A.; Katulak, N. A.; Katulak, N.A Emotional Intelligence in the Classroom: Skill-Based Training for Teachers and Students. In Applying Emotional Intelligence: A Practitioner's Guide; Psychology Press: New York, NY, USA, 2006 ; pp. 1-27.

46. Lee, A.; Kim, H.; Faulkner, M.; Gerstenblatt, P.; Travis, D.J. Work Engagement among Child-Care Providers: An Application of the Job Demands-Resources Model. Child Youth Care Forum 2019, 48, 77-91. [CrossRef]

47. Tonkin, K.; Malinen, S.; Näswall, K.; Kuntz, J.C. Building employee resilience through wellbeing in organizations. Hum. Resour. Dev. Q. 2018, 29, 107-124. [CrossRef]

48. Southwick, S.M.; Charney, D.S.; Chang, J.C.; Lockner, D.A.; Reches, Z. The Science of Resilience: Implications for the Prevention and Treatment of Depression. Science 2012, 338, 79-82. [CrossRef]

49. Vera, M.; Martínez, I.M.M.; Lorente, L.; Chambel, M.J. The Role of Co-worker and Supervisor Support in the Relationship Between Job Autonomy and Work Engagement Among Portuguese Nurses: A Multilevel Study. Soc. Indic. Res. 2015, 126, 1143-1156. [CrossRef]

50. McDonald, G.; Jackson, D.; Wilkes, L.; Vickers, M. Personal resilience in nurses and midwives: Effects of a work-based educational intervention. Contemp. Nurse 2013, 45, 134-143. [CrossRef]

51. Malik, O.F.; Shahzad, A.; Raziq, M.M. Work Engagement in the Face of Terrorism: The Moderating Role of Trait Resilience. J. Aggress. Maltreatment Trauma 2019, 29, 461-478. [CrossRef]

52. Turner, P. Employee Engagement in Contemporary Organizations: Maintaining High Productivity and Sustained Competitiveness; Palgrave Macmillan: Cham, Switzerland, 2020; ISBN 9783030363864.

53. Lopes, A.G.; Lau, H.; Nakandala, D.; Zhao, L. Using Research Methods in Human Computer Interaction to Design Technology for Resilience. J. Inf. Syst. Technol. Manag. 2016, 13, 505-524. [CrossRef]

54. Rudolph, C.W.; Allan, B.; Clark, M.; Hertel, G.; Hirschi, A.; Kunze, F.; Shockley, K.; Shoss, M.; Sonnentag, S.; Zacher, H. Pandemics: Implications for Research and Practice in Industrial and Organizational Psychology. Ind. Organ. Psychol. Perspect. Sci. Pract. 2020. [CrossRef]

55. Wang, C.; Cheng, Z.; Yue, X.-G.; McAleer, M. Risk Management of COVID-19 by Universities in China. J. Risk Financ. Manag. 2020, 13, 36. [CrossRef]

56. Rubbio, I.; Bruccoleri, M.; Pietrosi, A.; Ragonese, B. Digital health technology enhances resilient behaviour: Evidence from the ward. Int. J. Oper. Prod. Manag. 2019, 40, 34-67. [CrossRef]

57. Jones, G.R. Socialization Tactics, Self Efficacy, New comers Adjustments Organizations. Acad. Mang. J. 1986, $29,262-279$.

58. Bandura, A. Self-efficacy: Toward a unifying theory of behavioral change. Psychol. Rev. 1977, 84, 191-215. [CrossRef]

59. Taylor, H.; Reyes, H. Self-Efficacy and Resilience in Baccalaureate Nursing Students. Int. J. Nurs. Educ. Sch. 2012, 9, 1-13. [CrossRef] [PubMed]

60. Tan-Kristanto, S.; Kiropoulos, L.A. Resilience, self-efficacy, coping styles and depressive and anxiety symptoms in those newly diagnosed with multiple sclerosis. Psychol. Health Med. 2015, 20, 635-645. [CrossRef]

61. Djourova, N.P.; Molina, I.R.; Santamatilde, N.T.; Abate, G. Self-Efficacy and Resilience: Mediating Mechanisms in the Relationship Between the Transformational Leadership Dimensions and Well-Being. J. Leadersh. Organ. Stud. 2019, 27, 256-270. [CrossRef]

62. Wang, L.; Tao, H.; Bowers, B.J.; Brown, R.; Zhang, Y. Influence of Social Support and Self-Efficacy on Resilience of Early Career Registered Nurses. West. J. Nurs. Res. 2017, 40, 648-664. [CrossRef] [PubMed]

63. Galindo-Domínguez, H.; Pegalajar, M.; Uriarte, J.-D.-D. Mediator and moderator effect of resilience between self-efficacy and burnout amongst social and legal sciences faculty members. Rev. Psicodidáctica 2020, 25, 127-135. [CrossRef]

64. Hetzel-Riggin, M.D.; Swords, B.A.; Tuang, H.L.; Deck, J.M.; Spurgeon, N.S. Work Engagement and Resiliency Impact the Relationship Between Nursing Stress and Burnout. Psychol. Rep. 2019, 123, 0033294119876076. [CrossRef]

65. Gupta, P.; Srivastava, S. Work-life conflict and burnout among working women: A mediated moderated model of support and resilience. Int. J. Organ. Anal. 2020, ahead-of-print. [CrossRef]

66. Chen, I.-S.; Fellenz, M.R. Personal resources and personal demands for work engagement: Evidence from employees in the service industry. Int. J. Hosp. Manag. 2020, 90, 102600. [CrossRef]

67. Kaski, S.S.; Kinnunen, U. Work-related ill- and well-being among Finnish sport coaches: Exploring the relationships between job demands, job resources, burnout and work engagement. Int. J. Sports Sci. Coach. 2020, 1-10. [CrossRef]

68. Malik, P.; Garg, P. Learning organization and work engagement: The mediating role of employee resilience. Int. J. Hum. Resour. Manag. 2017, 31, 1071-1094. [CrossRef]

69. Nam, T. Technology Use and Work-Life Balance. Appl. Res. Qual. Life 2014, 9, 1017-1040. [CrossRef]

70. Ter Hoeven, C.L.; Van Zoonen, W.; Fonner, K.L. The practical paradox of technology: The influence of communication technology use on employee burnout and engagement. Commun. Monogr. 2016, 83, 239-263. [CrossRef] [PubMed] 
71. Duraisingam, V.; Roche, A.M.; Kostadinov, V.; Hodge, S.; Chapman, J. Predictors of work engagement among Australian non-government drug and alcohol employees: Implications for policy and practice. Int. J. Drug Policy 2020, 76, 102638. [CrossRef]

72. Philippe, F.L.; Lecours, S.; Beaulieu-Pelletier, G. Resilience and Positive Emotions: Examining the Role of Emotional Memories. J. Pers. 2009, 77, 139-176. [CrossRef] [PubMed]

73. Steinkopf, B.; Reddin, R.A.; Black, R.A.; Van Hasselt, V.B.; Couwels, J. Assessment of Stress and Resiliency in Emergency Dispatchers. J. Police Crim. Psychol. 2018, 33, 398-411. [CrossRef]

74. Bande, B.; Fernández-Ferrín, P.; Varela, J.A.; Jaramillo, F. Emotions and salesperson propensity to leave: The effects of emotional intelligence and resilience. Ind. Mark. Manag. 2015, 44, 142-153. [CrossRef]

75. Nilakant, V.; Walker, B.; Kuntz, J.; de Vries, H.P.; Malinen, S.; Näswall, K.; Van Heugten, K. Dynamics of organisational response to a disaster: A study of organisations impacted by earthquakes. In Business and Post-disaster Management; Routledge: London, UK, 2016; pp. 35-47.

76. Dai, Y.-D.; Zhuang, W.-L.; Huan, T.-C. Engage or quit? The moderating role of abusive supervision between resilience, intention to leave and work engagement. Tour. Manag. 2019, 70, 69-77. [CrossRef]

77. Kim, W.; Han, S.J.; Park, J. Is the Role of Work Engagement Essential to Employee Performance or 'Nice to Have'? Sustainability 2019, 11, 1050. [CrossRef]

78. Smith, B.W.; Dalen, J.; Wiggins, K.; Tooley, E.M.; Christopher, P.; Bernard, J. The brief resilience scale: Assessing the ability to bounce back. Int. J. Behav. Med. 2008, 15, 194-200. [CrossRef]

79. Zimet, G.D.; Dahlem, N.W.; Zimet, S.G.; Farley, G.K. Multidimensional Scale of Perceived Social Support. PsycTESTS Dataset 1988, 52, 30-41. [CrossRef]

80. Rhoades, L.; Eisenberger, R.; Armeli, S. Affective commitment to the organization: The contribution of perceived organizational support. J. Appl. Psychol. 2001, 86, 825-836. [CrossRef] [PubMed]

81. Venkatesh, V.; Morris, M.G. Davis User Acceptance of Information Technology: Toward a Unified View. MIS Q. 2003, 27, 425. [CrossRef]

82. Schaufeli, W.B.; Bakker, A.B.; Salanova, M. The Measurement of Work Engagement with a Short Questionnaire. Educ. Psychol. Meas. 2006, 66, 701-716. [CrossRef]

83. Ojo, A.O.; Fauzi, M.A. Environmental awareness and leadership commitment as determinants of IT professionals engagement in Green IT practices for environmental performance. Sustain. Prod. Consum. 2020, 24, 298-307. [CrossRef]

84. Fornell, C.; Larcker, D.F. Evaluating structural equation models with unobservable variables and measurements error. J. Mark. Res. 1981, 18, 39-50. [CrossRef]

85. Henseler, J.; Ringle, C.M.; Sarstedt, M. A new criterion for assessing discriminant validity in variance-based structural equation modeling. J. Acad. Mark. Sci. 2015, 43, 115-135. [CrossRef]

86. Hair, J.F.; Hult, G.T.M.; Ringle, C.M.; Sarstedt, M. A Primer on Partial Least Squares Structural Equation Modeling (PLS-SEM); Sage: Thousand Oaks, CA, USA, 2017.

87. Vidaver-Cohen, D. Moral Climate in Business Firms: A Conceptual Framework for Analysis and Change. J. Bus. Ethics 1998, 17, 1211-1226. [CrossRef]

88. Shmueli, G.; Sarstedt, M.; Hair, J.F.; Cheah, J.-H.; Ting, H.; Vaithilingam, S.; Ringle, C.M. Predictive model assessment in PLS-SEM: Guidelines for using PLSpredict. Eur. J. Mark. 2019, 53, 2322-2347. [CrossRef]

89. Preacher, K.J.; Hayes, A.F. Asymptotic and resampling strategies for assessing and comparing indirect effects in multiple mediator models. Behav. Res. Methods 2008, 40, 879-891. [CrossRef] [PubMed]

90. Zhao, X.; Lynch, J.G.; Chen, Q. Reconsidering Baron and Kenny: Myths and Truths about Mediation Analysis. J. Consum. Res. 2010, 37, 197-206. [CrossRef]

91. Social Distancing Keep a Safe Distance to Slow the Spread. Centers for Disease Control and Prevention. Available online: https:/ / www.cdc.gov / coronavirus/2019-ncov/prevent-getting-sick/social-distancing.html (accessed on 27 November 2020).

92. Chua, J.; Ayoko, O.B. Employees' self-determined motivation, transformational leadership and work engagement. J. Manag. Organ. 2019, 1-21. [CrossRef]

93. Caniëls, M.C.; Semeijn, J.H.; Renders, I.H. Mind the mindset! The interaction of proactive personality, transformational leadership and growth mindset for engagement at work. Career Dev. Int. 2018, 23, 48-66. [CrossRef]

94. Fawehinmi, O.O.; Yahya, K.K. Investigating the Linkage between Proactive Personality and Social Support on Career Adaptability Amidst Undergraduate Students. J. Bus. Soc. Rev. Emerg. Econ. 2018, 4, 81-92. [CrossRef]

95. Qing, M.; Asif, M.; Hussain, A.; Jameel, A. Exploring the impact of ethical leadership on job satisfaction and organizational commitment in public sector organizations: The mediating role of psychological empowerment. Rev. Manag. Sci. 2020, 14, 1405-1432. [CrossRef]

96. Ogbeibu, S.; Jabbour, C.J.C.; Gaskin, J.; Senadjki, A.; Hughes, M. Leveraging STARA competencies and green creativity to boost green organisational innovative evidence: A praxis for sustainable development. Bus. Strat. Environ. 2021, 2754. [CrossRef] 